\title{
Gestational Weight Gain and its Relation with Birth Weight of the Newborn \\ Meena Thapa, ${ }^{1}$ Rupa Paneru' \\ 'Department of Obstetrics and Gynaecology, Kathmandu Medical College, Sinamangal, Kathmandu, Nepal.
}

\section{ABSTRACT}

Introduction: Gestational weight gain is an important predictor of the health of the newborn. It is affected by body mass index of the women. This study was conducted to find out gestational weight gain according to Institute of Medicine 2009 recommendation and relationship of newborn birth weight to body mass index and gestational weight gain of the women.

Methods: It was cross sectional, hospital based study. The women, who attended at term pregnancy for delivery and having recorded first trimester body weight, were included in the study. Their body mass index was calculated and they were stratified into 4 groups according to body mass index. The gestational weight gain was calculated by subtracting first trimester body weight from body weight at the time of admission for delivery. All the women were followed till delivery. The newborn birth weight was taken immediately after delivery.

Results: A total of 227 women were enrolled in the study. More than half of the women had normal body mass index. There were 84 (37\%) overweight and obese women. Mean gestational weight gain was $10.21 \mathrm{~kg}$, and mean weight of the newborn was $3.05 \mathrm{~kg}$. There were equal number of women who had adequate weight gain and less weight gain according to recommendation. Excess weight gain was seen in 34 (15\%) women. Women of higher body mass index and women who had gain more weight during pregnancy had larger newborns.

Conclusions: Body mass index and gestational weight gain of the women were important predictors of birth weight of the newborn. There is a positive correlation between gestational weight gain of the women and birth weight of the newborn.

Keywords: birth weight; body mass index; gestational weight gain.

\section{INTRODUCTION}

Obesity is associated with various adverse effects on pregnancy. ${ }^{1}$ Overweight and obese pregnant women have increased risk of hypertensive disorder in pregnancy, gestational diabetes mellitus, cesarean section delivery, birth defects, premature delivery, jaundice and hypoglycemia in newborn and Neonatal ICU admission. Various factors are implicated as risk factors of maternal obesity. ${ }^{2}$
Weight gain during pregnancy is influenced by various factors like first trimester body mass index (BMI), age, parity, smoking status, race, ethnicity and physical activities. ${ }^{3}$ The weight gain during pregnancy is an important predictor of health of the newborn. ${ }^{2,4}$ Therefore,

Correspondence: Dr. Meena Thapa, Department of Obstetrics and Gynaecology, Kathmandu Medical College, Sinamangal, Kathmandu, Nepal. Email: meenathapa513@hotmail.com, Phone: +977. 9851060052 
the Institute of Medicine (IOM) has made a guideline for pregnancy weight gain according to pre-pregnancy BMI, which has been approved by WHO in $2009 .{ }^{5}$

This study was conducted to find out gestational weight gain according to IOM 2009 recommendation and relationship between birth weight of newborn with gestational weight gain and body mass index of the women.

\section{METHODS}

This is a cross-sectional, descriptive hospital-based study conducted in Gynaecology and Obstetrics Department of the Kathmandu Medical College. The study was conducted over the period of 2 months from Jan, 2017 to Feb, 2017. The study was done after approval from Institutional Review Committee of Kathmandu Medical College. The pregnant women who attended the Obstetric ward for delivery at term with antenatal checkup in Kathmandu Medical College since first trimester (before 12 weeks of gestation) were enrolled in the study. The pregnant women with multi-fetal gestation, preterm labor, diabetes mellitus, pregnancy induced hypertension, fetal congenital anomaly and thyroid disorder were excluded from the study. Their verbal consent for enrollment in the study was taken. The record of antenatal checkup was checked. The eligible women were interviewed regarding age, obstetric history and antenatal care visits. The weight at first visit (less than 12 week) was recorded from their antenatal care records. At admission, their weight in kilograms and height in meters were taken. They were followed till delivery. The weight (in $\mathrm{kg}$ ) of newborns were taken after delivery and recorded.

The first trimester Body Mass Index (BMI) was calculated by using following formula:

$\mathrm{BMI}=$ Weight in kilogram (First trimester) / (Height in meter $)^{2}$

The gestational weight gain (GWG) of the pregnant women was calculated by subtracting the weight in kilogram at first trimester from weight in kilogram at the time of enrollment in the study (at the time of admission for delivery).

Total sample size was 227 , which was calculated by following:

Sample size $(n)=Z^{2} \times \frac{S^{2}}{d^{2}}$

$Z=$ Confidence Level at $90 \%(1.96)$

SD -0.35

$d=$ Margin of Error at $10 \%$ of SD (0.0035)

Sample Size $(n)=227$
The data was recorded in Microsoft Excel spread sheet. The data was analyzed with SPSS version 20 . The significance of the finding was calculated by Chi-square test.

\section{RESULTS}

We studied 227 pregnant women. The mean age of the studied subjects was $26.15 \pm 4.54$ years. Among the women, $135(59.5 \%)$ of them were pregnant for first time (nulliparous), 76 (33.5\%) of them had given one birth already (parity one) and $16(7 \%)$ of them had had more than two deliveries before. According to BMI, majority of women 130 (57.2\%) had normal weight at first trimester, whereas $84(37 \%)$ of women were overweight and obese (Table 1).

\begin{tabular}{|ll|}
\hline Table 1. Anthropometric data of the women \\
\hline Body Mass Index (BMI) & $\mathbf{n}(\%)$ \\
$<18.5$ & $13(5.7)$ \\
$18.5-24.9$ & $130(57.26)$ \\
$25-29.99$ & $63(27.75)$ \\
$>29.9$ & $21(9.25)$ \\
Total & $227(100)$ \\
\hline
\end{tabular}

Mean weight gain during pregnancy was $10.21 \pm 4.18$ $\mathrm{kg}$. The weight gain during pregnancy was found adequate according to the recommendation in 96 $(42.2 \%)$ of subjects and another $97(42.7 \%)$ of them failed to gain weight according to the recommendation. Excess weight gain was observed in $34(15 \%)$ of women. Less weight gain was observed more in women belonging to normal first trimester, 77 (59.5\%), whereas three (23\%) of underweight, $13(20 \%)$ of overweight and three $(14.3 \%)$ of obese women had less weight gain than recommendation. No cases of excess weight gain were seen in women belonging to underweight group. Relatively more cases of excessive weight gain were seen in overweight and obese women (Table 2).

The mean birth weight of newborns was $3.040 \pm 0.42$ $\mathrm{kg}$ in this study. Mean birth weight of newborns from normal and underweight mother was $2.976 \pm 0.46 \mathrm{~kg}$. Significantly higher mean birth weight of newborns $(3.150 \pm 0.44 \mathrm{~kg})$ was found among overweight and obese mothers. Majority of newborn had normal birth weight. Low birth weight newborns were found in 26 $(11.5 \%)$ cases; whereas only four $(1.8 \%)$ newborns were macrosomic. Low birth weight newborns were observed in women of normal weight and overweight. No cases of low birth weight newborn were found in underweight and obese women. Macrosomic babies 
were observed significantly more ( $P$ value 0.000$)$ in obese women (Table 3).

\begin{tabular}{|llll|}
\hline \multicolumn{4}{|l|}{ Table 2. Gestational weight gain according to IOM } \\
2009 Recommendation. \\
\hline $\begin{array}{l}\text { Body Mass } \\
\text { Index of } \\
\text { women } \\
\text { ( }=227)\end{array}$ & $\begin{array}{l}\text { Number of } \\
\text { low weight } \\
\text { gain (\%) }\end{array}$ & $\begin{array}{l}\text { Number of } \\
\text { adequate } \\
\text { weight } \\
\text { gain }(\%)\end{array}$ & $\begin{array}{l}\text { Number } \\
\text { of excess } \\
\text { weight gain } \\
(\%)\end{array}$ \\
18.5 & $3(23.1)$ & $10(76.9)$ & 0 \\
$18.5-24.9$ & $77(59.5)$ & $39(29.9)$ & $14(10.8)$ \\
$25-29.9$ & $13(20.6)$ & $36(57)$ & $14(22.2)$ \\
$>29.9$ & $3(14.3)$ & $12(28.6)$ & $6(28.6)$ \\
Total & $96(42.3)$ & $97(42.7)$ & $34(14.9)$ \\
\hline
\end{tabular}

The relationship between gestational weight gain and newborn birth weight was studied using a scatter diagram. It was found that the newborn weight increased with increasing gestational weight gain.
There was a positive but weak relationship between them (correlation coefficient value 0.6) (Figure 1).

Figure 1. Relationship between gestational weight gain and birth weight of the newborn.

\begin{tabular}{|c|c|c|c|c|c|c|}
\hline \multirow{2}{*}{$\begin{array}{l}\text { Birth weight of the } \\
\text { newborn } \\
(n=227)\end{array}$} & \multicolumn{4}{|c|}{ Body Mass Index of the Women } & \multirow[t]{2}{*}{ Total $(\%)$} & \multirow{2}{*}{$\begin{array}{l}P \\
\text { value }\end{array}$} \\
\hline & $\begin{array}{l}\text { Underweight } \\
(n=13)\end{array}$ & $\begin{array}{l}\text { Normal Weight } \\
(n=130)\end{array}$ & $\begin{array}{l}\text { Overweight } \\
(n=63)\end{array}$ & $\begin{array}{l}\text { Obese } \\
(n=21)\end{array}$ & & \\
\hline $\begin{array}{l}\text { Low birth weight } \\
(<2.5 \mathrm{~kg})\end{array}$ & 0 & 20 & 6 & 0 & $26(11.5)$ & \\
\hline $\begin{array}{l}\text { Normal weight(2.5- } \\
3.99 \mathrm{~kg})\end{array}$ & 13 & 110 & 55 & 18 & $\begin{array}{l}197 \\
(87.7)\end{array}$ & \\
\hline $\begin{array}{l}\text { Macrosomic (4 kg and } \\
\text { above) }\end{array}$ & 0 & 0 & 1 & 3 & $4(1.8)$ & 0.000 \\
\hline Mean birth weight $(\mathrm{kg})$ & $2.99 \pm 0.21$ & $2.97 \pm 0.42$ & $3.12 \pm 0.43$ & $3.25 \pm 0.49$ & & 0.003 \\
\hline
\end{tabular}

\section{DISCUSSION}

According to the IOM 2009 recommendation, adequate GWG is 11.6-16.6 kg for underweight, 10.4-14.5 $\mathrm{kg}$ for normal weight, $6.8-11.5 \mathrm{~kg}$ for overweight and $5-9.1 \mathrm{~kg}$ for obese women. ${ }^{5}$ We found that only $42 \%$ percentage of women had adequate and nearly similar number of women had less weight gain than the recommendation. Surprisingly, less weight gain was observed in women belonging to women of normal weight. We have also found that increasing gestational weight gain was positively associated to newborn birth weight. Macrosomic newborns were found only among overweight and obese women.

The percentage of overweight and obese women was 37 in this study. Whereas, Upadhyaya $\mathrm{S}$ et al, ${ }^{6}$ from Kathmandu, reported that there were $22.3 \%$ and $58.2 \%$ of overweight women from two different ethnic groups. Slightly more percentage of overweight women were observed in the study done among the women of reproductive age attending a gynaecology clinic in Kathmandu. ${ }^{7}$ A lesser number of overweight women were found by the following studies. A national representative survey has shown that only $7.4 \%$ of women were overweight in Nepal. ${ }^{8}$ Another multicentric study from developing countries has shown that only $0.1 \%$ of non-pregnant women were overweight in South Asian region. ${ }^{9}$ Less number of overweight women were found in these studies, might be due to their involvement of women of all age groups and moreover these studies were conducted almost two decades ago. Overweight and obese women were found less among Thai women ${ }^{10}$ than our studied population, but much higher rate of overweight and obese women was reported from Northern California. ${ }^{11}$ 
The weight gain during pregnancy was varied from 0 to $25 \mathrm{~kg}$ with mean weight gain of $10.5 \pm 4.18 \mathrm{~kg}$ in our studied population. Mean gestational weight gain was found slightly less in the study done in Patan Hospital. ${ }^{12}$ whereas Indonesian pregnant had slightly more weight gain than our studied pregnant women. ${ }^{13} \mathrm{~A}$ multi-centric study done in Australia and New Zealand reported 13. $9 \mathrm{~kg}$ of gestational weight gain among nulliparous women, which is higher than our study. ${ }^{2}$ The study done in USA, has reported a much higher gestational weight gain among their women. ${ }^{14}$ The reason may be that Australian and American women have higher BMI than our women.

As our findings, Thai women also had less number of women having adequate gestational weight gain, ${ }^{10}$ whereas, nearly $97 \%$ of Nigerian pregnant had less weight gain than the recommendation. ${ }^{4}$ The reason behind this may be that Nigerian women had less BMI than our women. Excess GWG was seen only in overweight and obese women in our study. Similar finding has been reported from study done among European and Australian pregnant women. They found that nearly three quarters of the overweight and obese pregnant women had excess GWG than the recommendation. ${ }^{2}$ Very high number of women (66.1\%) from California had excess GWG ${ }^{11}$ whereas, only seven percentages of obese Nigerian women had excess GWG than the recommendation. ${ }^{4}$

We found that, the mean birth weight of newborn was $3.04 \pm 0.42 \mathrm{~kg}$. The study among two ethnic groups of women from Kathmandu ${ }^{7}$ and another study from Patan Hospital ${ }^{12}$ have reported almost similar mean birth weights of newborns. We found that almost $86 \%$ of newborn had normal birth weight. Macrosomic babies were found only among overweight and obese women. Sizes of the newborn were found larger as the BMI of the women had increased. Low birth weight newborns were found more among normal weight women. It may be because almost $60 \%$ of these women had less weight gain than the recommendation. We had also found that there was positive relationship between
GWG and newborn birth weight. Similar findings were reported in a study of maternal weight gain and infant birth weight among 159 pregnant women. They also found that women having higher GWG had larger babies than those who gained less weight during pregnancy. ${ }^{15}$ A positive linear relationship between GWG and the newborn weight was also found in the study from Patan Hospital ${ }^{12}$ and Indonesia. ${ }^{13}$ In Brazil, $13 \%$ of newborns born from mothers having excess weight gain were macrosomic, whereas women having appropriate weight gain had less than $1 \%$ macrosomic babies. They also found that there was a positive correlation between GWG and newborn birth weight. ${ }^{16}$ Another study by Sridhar et al, ${ }^{11}$ had also found that excess GWG was associated with large-for-date newborns, and less weight gain during pregnancy was related with small-for-date newborns.

To calculate accurate gestational weight gain, prepregnancy weight is necessary, but it is difficult to find pre pregnancy weight in our women and average first trimester weight gain is very less so that first trimester weight was utilized to calculate gestational weight gain.

\section{CONCLUSIONS}

Higher BMI of the women is related with excess weight gain during pregnancy and larger weight newborn. There is a positive correlation between gestational weight gain of the women and birth weight of the newborn. So, it can be concluded that early pregnancy BMI and GWG are important predictors of birth weight of the newborn.

\section{ACKNOWLEDGEMENTS}

We would like to acknowledge Dr. Naresh Manandhar for helping us in data analysis and Prof. Rachana Saha for editing this manuscript.

\section{Conflict of Interest: None.}

\section{REFERENCES}

1. Martin RR, Hyde MJ, Modi N. Maternal obesity and infant outcome. Early Human Development. 2010 Nov;86(11):715-22. [Full Text]

2. Restall A, Taylor RS, Thompson JMD, Flower D, Dekker GA, Kenny LC, et al. Risk factors for excessive gestational weight gain in a healthy, nulliparous cohort. Journal of Obesity. 2014:1-9. [Full Text | DOI]
3. Abraham B, Carmichael S, Selvin S. Factors associated with the pattern of maternal weight gain during pregnancy. Obstet Gynecol. 1995 Aug;86(2):170-6. [PubMed]

4. Esimai OA, Ojofeitimi E. Pattern and determinants of gestational weight gain: an important predictor of infant birth weight in a developing country. Global Journal of Health Science. 2014;6(4):148-54. [Full Text]

5. Weight gain during pregnancy. Committee opinion No. 548 . American college of Obstetrician and Gynecologist. Obstet Gynecol. 2013;121:210-2. [Full Text] 
6. Upadhaya S, Bichha RP, Sherpa MT, Shrestha R, Panta PP. Association between maternal body mass index and the birth weight of neonates. Nepal Med Coll J. 2011;13(1):42-5. [PubMed]

7. Padhye SM. A study of body mass index (BMI) of Nepalese women attending gynaecology clinic. J Nepal Medical Assoc. 2007;46(168):185-8. [PubMed]

8. Balarajan Y, Villmor E. Nationally representative surveys show recent increases in the prevalence of overweight and obesity among women of reproductive age in Bangladesh, Nepal, and India. The Journal of Nutrition. 2009 Sep:2139-43. [PubMed]

9. Martorel R, Khan LK, Hughes ML, Grummer-Strawn LM. Obesity in women from developing countries. European Journal of Clinical Nutrition. 2000;54:247-52. [Full Text]

10. Sunsaneevithayakul $\mathrm{P}$, Titapant $\mathrm{V}$, ruangvutilert $\mathrm{P}$, Sutanawibul A, Phatihattakorm C, Wataganara T, Talungchit $\mathrm{P}$. Relation between gestational weight gain and pregnancy outcomes. J Obstet. Gynaecol. Res. 2014;40(4):995-1001. [PubMed]
11. Sridhar SB, Xu F, Hadderson M M. Trimester specific gestational weight gain and infant size for gestational age. PloS ONE. 2016 Jul; 11(7):1-7. [Full Text]

12. Shrestha I, Sunuwar L, Bhandary S, Sharma P. Correlation between gestational weight gain and birth weight of the infants. Nepal Med Coll J. 2010;12(2):106-9. [ubMed]

13. Lumbanraja S, Lutan D, Usman I. Maternal weight gain and correlation with birth weightof infants. Procedia Social and Behavioral Sciences. 2013;103:647-56. [Full Text]

14. Brown JE, Murtaugh MA, Jacob DR Jr, Margellos HC. Variation in newborn size according to pregnancy weight change by trimester. Am J Clin Nutr. 2002;76:205-9. [PubMed]

15. Shapiro C, Sullia VG, Bush J. Effect of maternal weight gain on infant birth weight. J Perinat Med. 2000;28(6):428-31. [PubMed]

16. Costa BMF, Paulinelli RR, Barbosa MA. Association between maternal and fetal weight gain; cohort study. Sao Paulo Med J. 2012;130(4):242-7. [Full Text] 